\title{
'If I'm Like Them, They Will Accept Me More': How New Zealand Immigrants Negotiate and Perform Gendered Social Identities'
}

SONYA HAMEL

Immigrants bring a wealth of culturally constructed ideologies with them into the target culture, where they are met by a different set of normative ways. Gender ideologies, for instance, are socially constructed within a particular culture, thus inviting a redefinition of adult immigrants' gender identities once they live long-term in the target culture. This ethnographic study, from a sociolinguistic perspective, investigates the processes of negotiation and performance of new gendered identities of twenty adult long-term immigrants to New Zealand. Three social domains are here considered as important sites for such discourse practices: intimate relationships, parent-child relationships and friendship networks. This study takes the poststructuralist approach to identity, viewing identity as a construct in conjunction with interlocutors and the target culture at large.

\section{New Zealand immigrants' gender ideologies}

The term 'gendered identities' as it is used in this article, nowadays a basic tenet of the poststructuralist and social constructionist approaches to identity, is based on Butler's idea that gender is located in the 'doing' and 'performing' rather than in the inherent 'being' of a person. ${ }^{2}$ This article addresses one aspect of discursive (re)construction of identity, transformations of gender performance, situating it within a language socialisation perspective that views second-language learning as an essentially social process. ${ }^{3}$ This process recognises that the relationship between the learner and the learning context is dynamic and constantly changing. This article presents the transformation processes of gender performance between source-culture and target-culture conceptions of normative masculinities and femininities on an individual, subjective level, without making claims to generalisations. Participants' discursive practices are examined in three different social contexts: intimate relationships; parent-child relationships; and the friendship network. This separation of social contexts originates in social network analysis and has been used by sociolinguists since the 1980s to explain 
individual or group social behaviour. ${ }^{4}$ Gender is seen as structuring social contexts and, by implication, language use in a given context, ${ }^{5}$ and these three contexts, together with the workplace and education contexts, tend to be salient sites where traditional gender expectations are most often questioned, negotiated, and contested. ${ }^{6}$ This study examines the extent to which the three contexts are domains in which informants negotiate and construct new gendered identities. It also evaluates the willingness of participants to critically examine the gender expectations by which they had lived or continue to live. The two more formal domains of work and education are excluded as a focus of this paper due to a relative dearth of data collected in this study.

Facing new gender ideologies (the term 'gender ideologies' is taken from Cameron's ${ }^{7}$ suggestion that it is speech communities that produce gendered styles and ideologies to which individuals are socialised in their formative years), is tied to possibilities of new ways of self-expression for adult immigrants, whereby they may opt for assimilation or resistance to target-culture gender values, or position themselves anywhere between the two extremes. The desire to assimilate may be prompted by a rejection of source-culture gender ideologies and discursive practices, where individuals feel devalued or limited in their self-expression, while simultaneously perceiving target-culture gender ideologies to be more liberating and offering more choices for new identities. A position of resistance or part-resistance to target-culture gender ideologies may, on the other hand, be caused by what individuals may perceive as more liberal source-culture values. The co-constructed (or jointly constructed with interlocutors) nature of discourse, as 'discourse' is defined in this study, presumes that identity-construction processes in various social domains do not happen in isolation, but that the interlocutor(s), and indeed the target-culture context, play an important role in the process.

New Zealand has long been a desirable destination for immigrants, and it continues to attract increasing numbers of people willing or obliged to leave their native countries. Because of its relatively recent history of colonisation and a consequent lack of a shared deep-seated (Western) cultural tradition, New Zealand is a new and interesting setting in which to conduct linguistic research into immigrants' construction of new gendered identities. Previous studies of language and gender in an Australasian setting have focused on gendered speech in a variety of social settings, especially the workplace ${ }^{8}$ and on women and language in Australian and New Zealand society. ${ }^{9}$ This study differs from these in that it departs from a focus on dichotomous gendered speech and the 'construction of gendered ethnolinguistic identities and the survival of the respective community languages'. ${ }^{10}$ Instead, it presents both male and female immigrant informants' reported experiences 
of encountering the target-culture gender ideologies and how they live with any ensuing tensions and difficulties in adjusting to them. Constructivist, critical-feminist, and poststructuralist research paradigms suggest that many of the assumptions about who uses what forms have little to do with gender. They also propose that research on the complex, multiple, and co-constructed identities operating in research studies can reveal that the patterns ascribed to women also appear in the speech of men. ${ }^{11}$

\section{Previous studies}

Contemporary linguistic research on language and gender has arisen out of three major gender/feminist theories: Lakoff's ${ }^{12}$ deficit theory, highlighting the perceived negativity of the ways in which women's language does not match the 'standard' of men's language; the dominance framework, linking negative evaluations of women's language to their social domination by men; ${ }^{13}$ and the difference framework, suggesting that men and women are socialised into different communicative styles. ${ }^{14}$ In addition, Faludi's ${ }^{15}$ work on masculinity proposes that men's identities have become more problematic as a result of changes in society, so that masculinity can no longer be viewed as the unproblematised norm against which female language is scrutinised and problematised. ${ }^{16}$ Gender researchers and theorists such as Cameron, ${ }^{17}$ Coates, ${ }^{18}$ Bucholtz, Liang and Sutton, ${ }^{19}$ Hall \& Bucholtz, ${ }^{20}$ Freed,${ }^{21}$ Holmes, ${ }^{22}$ McElhinny, ${ }^{23}$ Pauwels, ${ }^{24}$ and Winter and Pauwels ${ }^{25}$ have since argued for the inclusion of gender interacting with race, ethnicity, sexuality, social class, nationality, and other dimensions of social identity. As a consequence, studies have shifted from 'viewing gender as an individual and generalizable trait to viewing gender as a social construction within specific cultural and situational contexts, ${ }^{26}$ away from an essentialist and towards a poststructuralist approach to identity. The poststructuralist approach to identity, which informs this study, sees identity as socially constructed, a self-conscious and ongoing narrative, a performance, co-constructed with others, in which individuals negotiate new subject positions in an often conflictive process, at the crossroads of past, present and future. ${ }^{27}$

In recent years, many researchers studying the interface of multilingualism, second-language learning, and gender have criticised the hitherto monolingual bias in the study of language and gender. ${ }^{28}$ This bias completely ignores the fact that more than half of the world's population is bi- and multilingual. They point out that the meaning of gender is not shared across cultures, nor is it fixed and unproblematic. ${ }^{29}$ The biological dichotomy of male/female into which all flora and fauna, including humankind, have long been categorised has been superseded by viewing gender as something we 'do' and perform in interaction with others, rather than something we 'are'. ${ }^{30}$ 
Social constructionist Vivienne Burr ${ }^{31}$ claims that social identity arises out of interactions with others, that it is based on language, and that it is constructed from the discourses culturally available to us. Thus, individuals bring their own culturally constructed assumptions and rules of communication and apply them in intercultural encounters to understand what is going on. As a result, cross-cultural interactions between immigrants and native speakers may suffer from a lack of shared values and ideologies. ${ }^{32}$ Communication and culture influence each other, ${ }^{33}$ since every individual is a product of their culture and history, and all possible ways of understanding are historically and culturally relative. ${ }^{34}$

This study tests the hypothesis that cross-cultural differences in gender ideologies imply that adult immigrants enter a renegotiation process in which their gendered identities, acquired in their source culture through a socialisation process, are adjusted in some measure to the gender ideologies they perceive to be prevalent in the target culture. The renegotiation process of cultural adaptation has been called complex and difficult..$^{35}$ A host of migration and oral history literature within the New Zealand setting attests to these complexities. ${ }^{36}$

\section{The participants}

The main selection criteria for participants for this study were that they had immigrated to New Zealand as adults and that they had lived here for at least two years at the time of the interview. The rationale for these choices was firstly that informants had been fully socialised into their source-culture gender ideologies and secondly to ensure that participants had been in New Zealand long enough to become aware of intercultural differences. Two years was considered a minimum period of exposure to the target culture, because 'the demands on the immigrants to learn the second language and cultural practices of the new society would be greater for more recent immigrants'. ${ }^{37}$ A further criterion in the selection process was trying to achieve a gender-balanced group of informants, since the aim of this study was to hear from both male and female immigrants about their individual identity-construction processes in the face of the differing gender ideologies that they perceive to be prevalent in the target culture.

The study achieved an acceptable balance in respect of ages, cultural backgrounds (Table 2), lengths of stay in the target culture, as well as marital (Table 3) and parental statuses.

The participants' biographical data are collated in Table 1: 
If I'm Like Them, They Will Accept Me More

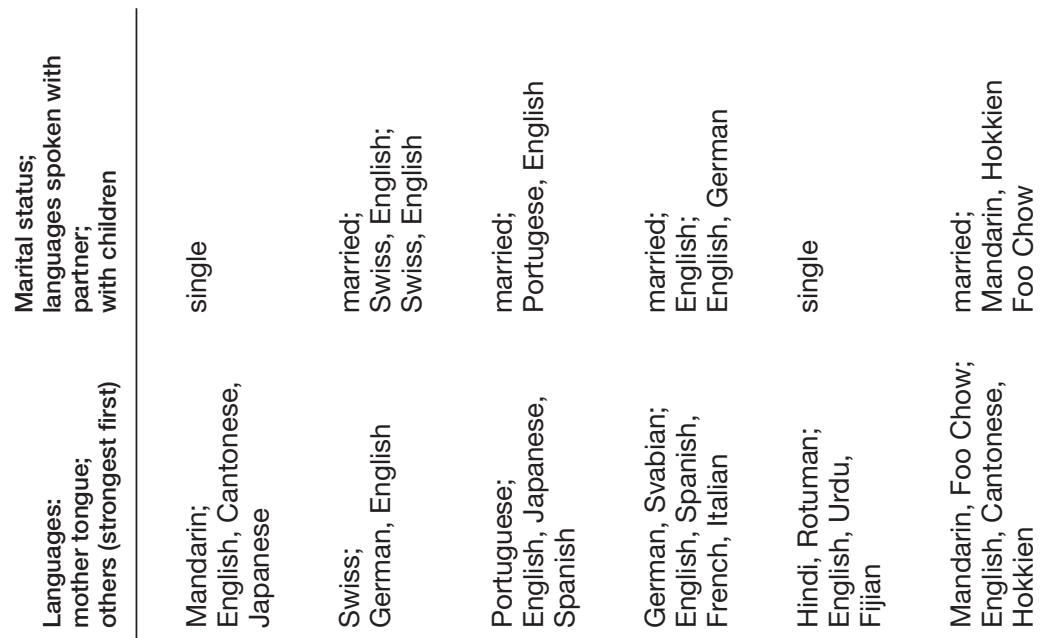

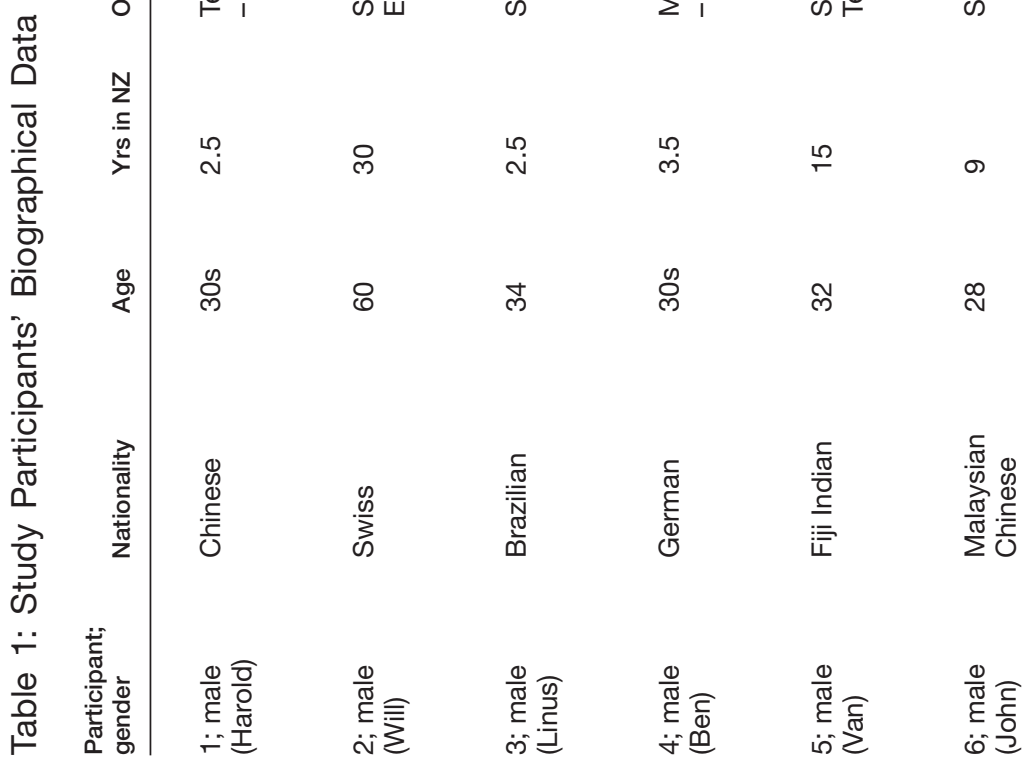


Journal of New Zealand Studies
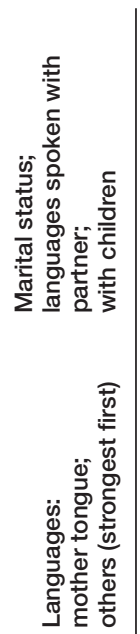

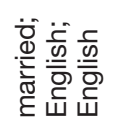<smiles>[Tl]</smiles>

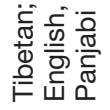

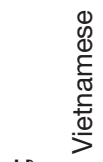

过㐫 है एँ

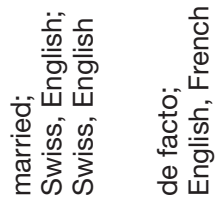

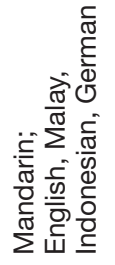

iी ๗ळ

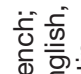
亡ับ

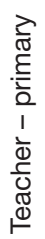

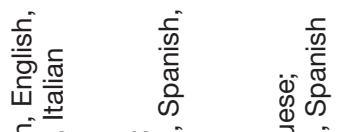

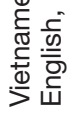

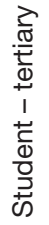

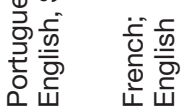

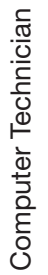
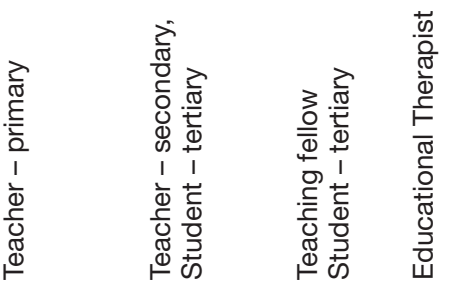

요

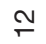

$\Lambda$

N

윰

$\infty$

ल $\stackrel{\infty}{\sim}$

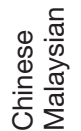

$\sum_{\infty}^{\infty}$

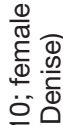

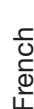

$\frac{0}{\frac{1}{6}}$

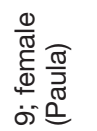
ตำ

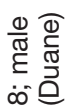

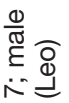

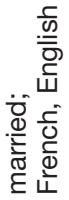

$\frac{\frac{c}{0}}{\frac{0}{0}}$ 
If I'm Like Them, They Will Accept Me More

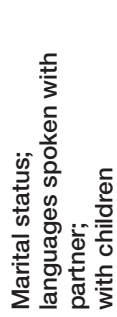

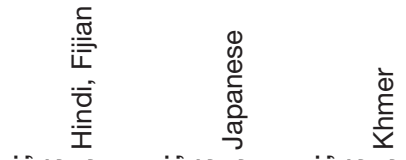

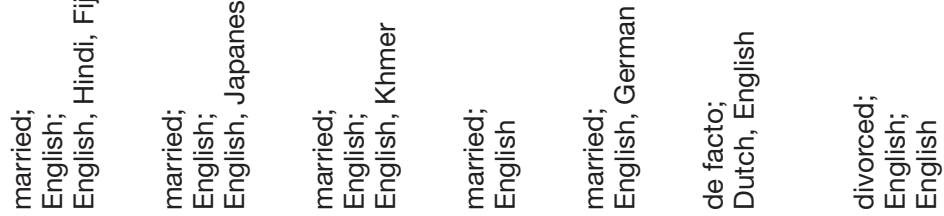

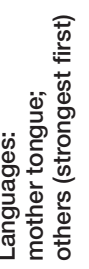

迹

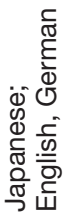

ॠ

बॄ⿺ 丶

$\frac{\frac{c}{\infty}}{\frac{\sqrt{\pi}}{\text { ली }}}$

离

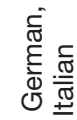

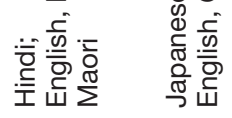

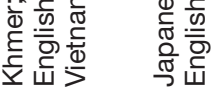

这

$\approx \frac{c}{\tilde{c}}$

in $\frac{\tilde{\omega}}{\tilde{c}}$

产 $\frac{1}{\square}$

员 ब

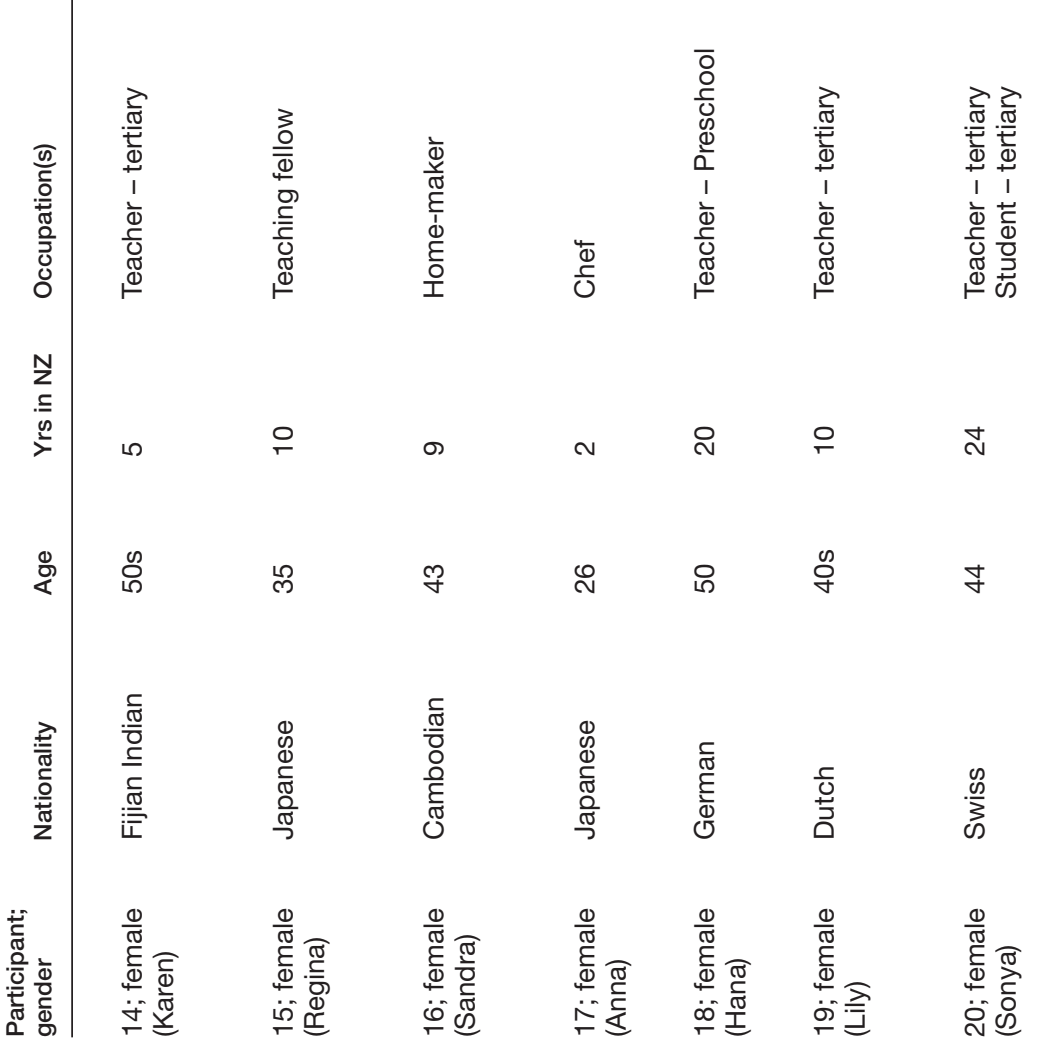


Journal of New Zealand Studies

Table 2: Study Participants' Cultural Backgrounds

\begin{tabular}{|c|c|c|c|}
\hline Asians: 8 & Europeans: 7 & South Americans: 2 & From elsewhere: 3 \\
\hline 1 Chinese & 3 Swiss & 2 Brazilians & 2 Fijian Indians \\
\hline 2 Malaysian Chinese & 2 Germans & & 1 French Canadian \\
\hline 1 Tibetan & 1 French & & \\
\hline 1 Vietnamese & 1 Dutch & & \\
\hline \multicolumn{4}{|l|}{2 Japanese } \\
\hline 1 Cambodian & & & \\
\hline
\end{tabular}

Table 3: Cultural Backgrounds of Study Participants' Life Partners

\begin{tabular}{llll}
$\begin{array}{lll}\text { Male Participants' } \\
\text { culture }\end{array}$ & Partner's culture & $\begin{array}{l}\text { Female Participants' } \\
\text { culture }\end{array}$ & Partner's culture \\
\hline Brazil & New Zealand & France & New Zealand \\
Germany & USA & Brazil & New Zealand \\
Tibet & Australia & Fiji & New Zealand \\
Vietnam & New Zealand & Japan & New Zealand \\
Switzerland & Switzerland & Cambodia & New Zealand \\
Malaysia & Malaysia & Japan & New Zealand \\
& & Germany & New Zealand \\
& & Switzerland & Switzerland \\
& & Holland & Holland \\
& & French Canada & French Canada
\end{tabular}

Neither participants' socio-economic backgrounds nor their educational levels are included in this study as variables, although it is evident at a glance that most informants have a high level of education; this is perhaps an incidental feature due to the fact that the snowballing method of informant-gathering happened within a university setting.

\section{Social domains}

Five social contexts tend to be heavily gendered in many societies, according to Piller \& Pavlenko: ${ }^{38}$ intimate relationships, parent-child relationships, friendship networks, the workplace and education. The workplace domain as a site where gender identities are contested has featured in recent research elsewhere ${ }^{39}$ and is excluded here because of the relative paucity of relevant interview data gathered from these informants. Informants generally shared their experiences of gender identity re-negotiation processes in the three private domains featured in this paper. 


\section{Intimate relationships}

The view of performative gender follows Butler's ${ }^{40}$ postmodern conceptualisation of gender as a performance that creates a gendered identity in the very act. This conceptualisation rejects the notion that gender is determined by the biology of sex. Cross-cultural intimate relationships are considered one of the most difficult areas for negotiation of an authentic performance of gender, ${ }^{41}$ since both men and women may find it extremely difficult, in this most private of domains, to depart from traditional gender roles and to embrace new ones. The socially constructed gender roles of intimate relationships, modelled primarily by one's parents and later by peer groups, are the departure point for negotiating gendered performances in cross-cultural encounters in this domain. Adult immigrants in cross-cultural intimate relationships may come to realise that it is not only their performance of gender that needs adjusting to new gender ideologies; interpreting others' gender performances may also prove problematic: 'Immigrants need to learn more than just a set of grammatical rules and how to apply them to new vocabulary: new discourses come with new ideologies and practices of embodiment. ${ }^{42}$ The possibilities of self-expression afforded to individuals by different languages are endless, particularly when one examines the ways in which gendered performances in intimate relationships may be transformed in the process of second-language socialisation. ${ }^{43}$

\section{Parent-child relationships}

In parent-child relationships in multilingual settings, change is often inflicted on children as well as initiated by children. ${ }^{44}$ First-generation immigrants often find themselves positioned between tradition and change, particularly when children are born into the target culture. The cultural transition may have negative effects, such as the decline of parental authority and status. ${ }^{45}$ Alternatively, immigrants may come to reject a particular ethnic, cultural or gendered identity from their source culture, which may lead to emotional and cultural tension between children and parents. Cameron ${ }^{46}$ points to the paradoxical situation in which many immigrants find themselves with regard to cultural assimilation: while beneficial socially and economically, it may also undermine their way of life, their values, their beliefs, and ultimately their ethnic and cultural identity. It is exactly these cultural values that many immigrant parents wish to pass on to their children, while they simultaneously try to facilitate their children's entry into the majority language and culture. ${ }^{47}$

Language choices made to suit (childless) couples may be revisited once children are born. First and childhood languages are often constructed as intimate and emotionally expressive in relation to parenting, allowing access to aspects of self not necessarily available in the language(s) learned 
later. ${ }^{48}$ Many cultures' images of ideal femininity place women in the role of 'transmitters of the home language, and of cultural, ethnic, and religious traditions' ${ }^{49}$ It is not surprising to find that minority languages are better maintained if the mothers are the minority speakers and choose to transmit the minority language.$^{50}$ Furthermore, Burck ${ }^{51}$ suggests that a father's decision to use his L1 with his children is more likely to be influenced by his wife/ partner's use of the language with the children than by pressure from outside the family unit. Issues around language use within families are significantly interlinked with gendered identity-construction in parents, in particular with how mothering and fathering have been conceptualised. ${ }^{52}$

Parenting in the mother tongue may allow a greater sense of intimacy between a parent and children; whereas parenting in the target language could offer opportunities to diverge in parenting from their own experiences, thus facilitating a new gendered identity-construction. Immigrants wishing to distance themselves from the parenting ideologies of their own parents may opt for a parenting role in another language in order to achieve this distancing. Single immigrants to New Zealand, who are not necessarily surrounded and supported by a social network of their own culture, may feel isolated and under much greater pressure to assimilate to target-culture gender ideologies as parents. Among the wealth of migration literature of New Zealand, Bönisch-Brednich's ${ }^{53}$ 'Keeping a Low Profile: An Oral History of German Immigration to New Zealand' stands out as one example of an in-depth discussion of the impact that the migration experience has on gender identities.

\section{Friendship networks}

Friendship networks in multilingual contexts are public testing grounds for immigrants in which to risk a variety of discursive practices without the pressures or restrictions a more formal domain such as the workplace setting may pose. Other research has focused on the appropriations of a language used in a friendship network, appropriations that construct not only gender but also race. ${ }^{54}$ It illustrates that 'a gendering of languages very often goes hand in hand with racist stereotyping of their speakers'. ${ }^{55}$ There is no simple mapping between gender and linguistic practices in the multilingual context, especially in this study that examines individual immigrants' experiences rather than an immigrant group's. Single immigrants to New Zealand enter a majority language environment in which there seems little choice but to assimilate to the target language and, by default, to adapt to the target culture. Nonetheless, immigrants always have choices as to the degree of adjustment and ways in which they make use of discursive resources in their interactions with others, in friendship circles or elsewhere. 


\section{Method}

The data for this qualitative research study was collected over a threemonth period in 2004 by means of a single semi-structured, face-to-face interview with 19 participants. The informants are either friends, work or study colleagues of the present writer, where a rapport with the researcher was already established (and thus the power dimensions between 'expert' researcher and 'lay' informants were/are reduced ${ }^{56}$ ), or are friends-of-friends recruited through the 'snowballing' method as advocated by Milroy. ${ }^{57}$ The interviews were conducted in English, and ranged in time from 15 to 90 minutes. All interviews were audio-recorded and transcribed in full, the data then coded and analysed in line with Grounded Theory guidelines. ${ }^{58}$ Pseudonyms are used in the transcriptions and in the data presented here to preserve participants' anonymity. As a qualitative researcher engaged in empirical data analysis, the present writer considers self-reflexivity to be central to the research process. ${ }^{59}$ Thus, a self-report was added to the corpus of data, acknowledging the importance of juxtaposing first-hand experience with the participants' self-reported experiences. ${ }^{60}$ The author is a second-language learner of English and an adult immigrant to New Zealand herself and thus very likely shares many of the participants' experiences of acculturation to the target culture. She thus becomes an 'insider' researcher. The researcher's interests, position as an adult long-term immigrant, and to a certain degree her assumptions about immigrant lives, all inform this reflexive stance. She agrees with $\mathrm{Wei}^{61}$ that the identity of the researcher affects the aims and objectives of the research, the relationship with the people being studied, and the choice of theoretical and methodological perspective.

Along with Grounded Theory methods, the main analytical concept used in this study was self-positioning, which Davies and Harre ${ }^{62}$ view as 'the process by which individuals are situated as observably and subjectively coherent participants in the story lines'. In this study, the process of selfpositioning is seen as closely linked to how dominant ideologies of language and gender position the narrators (in this case the interviewees) and how individuals internalise or resist these positions. ${ }^{63}$

Face-to-face interviews are regularly used in qualitative studies involving issues of subjectivity, because they allow a degree of interaction between researcher and participant that other methods, such as questionnaires, census data, or narrative analysis, do not offer. In particular, they facilitate a dialogic exchange of experiences based on the shared difficulties faced in the target-culture setting. Dialogues are not just with other people but also with oneself, in making sense of one's experiences. Identities are multiple and flexible, and the individual is always in the process of becoming. ${ }^{64}$ Thus, 
the interview itself provides a space within which identity-construction takes place.

Participants were given a list of questions eliciting biographical data, plus three interview questions that provided a departure point for the semistructured interviews. All three questions are open-ended and encourage participants to speak freely and openly on any aspect of their choosing within the parameters of the research topic.

Question 1. 'What does it mean to be a woman/man in your culture?' addresses participants' cultural roots and their source-culture gender ideologies. In order to be able to gain an insight into participants' acculturation processes in the target culture, as well as the particular difficulties each of the participants needs (or needed) to overcome, it was deemed important to hear from individuals about their source cultural experiences in respect to gender ideologies.

Question 2. 'In what ways is the New Zealand culture different from yours, focusing particularly on the idea of gender?' elicits information from the participants about their perceived place on the intercultural continuum. This question assumes the premise that culturally constructed gender ideologies differ and that immigrants have become aware of these cultural differences.

Question 3. 'In what ways did you have to change, living in New Zealand?' prompts participants to share experiences of adjustments from their sourceculture gender ideologies to target-culture gender ideologies.

Data analysis was conducted through a search of the coded transcripts for the key sites of transformations of gender performance and the links between language and gender. Participants' information was then grouped into the social domains described above, and these were closely scrutinised. Attention was paid not only to evidence of gendered identity re-negotiation and construction but also to general, non-gender-specific identity-construction that illuminates differences among the social domains.

\section{Discussion of intimate relationships}

This section presents some of the participants' reported experiences in their cross-cultural intimate relationships, one of the most difficult domains for the construction of an authentic new gendered identity, according to Pavlenko. ${ }^{65}$ Given that gender identity is a social and cultural construct and that individuals are socialised into constructed gender ideologies, target-culture masculinities or femininities may differ from those that adult immigrants wish to reproduce. Such changes in gender roles may lead to tensions and difficulties between partners in cross-cultural intimate relationships. 
Harold, originally from China and a New Zealand resident for two-and-ahalf years, is aware of the differences in gender roles cross-culturally and the societal expectations prevalent in the target culture, which are informing his new (as yet single) gendered identity: 'I'm not going to take the traditional role at all, probably one of the reasons that I'm here is because I'm in some way between the East and the West, and New Zealand is a Western country ... man and woman must be equal ... so in the future when I get a family I'd still want to make it like a two persons work together and no one is going to dominate at all.' Harold's willingness to adjust to new gender ideologies, evident in his self-positioning as between East and West, arises from a desire to integrate into the target culture, perceived to have more liberal views on equality between spouses, and to become an accepted member of this group.

Immigrants' understanding of gender is at first historically and culturally relative to their source culture and dependent on the social arrangements in that culture, ${ }^{66}$ until it is perceived as necessary (or desirable, as in Harold's case) that adjustments to target-culture values be made. The trigger for change may be a cultural difference in gender ideology that is forced upon immigrants by their interlocutors, often with undesirable consequences. Sola, originally from France and a New Zealand resident for 12 years, recounts such a situation: 'After a little while I started to think I mustn't be the same, I must have either put on weight or don't look good, or I don't dress well enough, but the men were not looking at me the same way, they were not interacting with me at all the same way. I like the humour around sex and sexual references and things like that ... that was gone, finished.' Sola finds that her native culture supports gender ideologies different from the ones she finds in New Zealand. Generally speaking, French men tend to compliment women on their appearance openly and publicly, and French women tend to expect this admiration as their due. In a different cultural environment, Sola has come to feel the lack of such a socially and culturally co-constructed ideology.

Assimilation to target-culture practices would mean the loss of a part of Sola's culture she clearly finds difficult to relinquish. Her (male) New Zealand interlocutors, being co-constructors of her new gendered identity, enforce target-culture gender ideologies in this situation: the behaviour Sola describes might be interpreted as sexist in the New Zealand gender ideology. Sola's example suggests that immigrants may find themselves in situations where their previous subjectivities cannot always be reproduced. In Sola's case this is perceived as a negative outcome; however, for some immigrants this non-transference is a desirable goal, particularly for those whose source culture denies them autonomous gendered identities. 
The use of a high-pitched voice as an important way of performing female gender in Japanese society or the appearance of being 'small, weak, and child-like in an attempt to display their cuteness', are often cited as cultural constraints by Japanese women crossing national and cultural boundaries as adults. Regina, originally from Japan, a New Zealand resident for 10 years, and now married to a New Zealander, confirms that the target-culture gender ideologies she encounters are unlike the Japanese gender ideologies she knows: 'Because I come from a conservative place, I noticed that [here] women have more power and they are more equal. I find that lots of wives "wear pants". In Japan I think that men sort of command, tell women what to do and women have to obey, but here's more of a two-way communication and more equal.' Elsewhere in the interview, Regina revealed that she had made a positive choice to move away from the strictly patriarchal society into which she was socialised and toward the power and equality that she perceives New Zealand women as possessing. Regina seems to find in the New Zealand culture increased opportunities for (re)constructing a new gender identity, highlighting two-way communication among spouses and equality in intimate relationships as desirable goals for her.

Negotiation of new gender identities is problematised cross-culturally, because different cultures do not share all the norms that native speakers come to take for granted. Sandra, originally from Cambodia, a New Zealand resident for the past nine years and married to a New Zealander, has difficulty constructing a new gendered identity. Her process of socialisation in a different language and culture is taking place later in life, and she finds transformation therefore more difficult to negotiate: 'I have become comfortable to talk to my husband, my opinions, to raise my voice sometimes, to let him do the dishes and hang out clothes. I had to adapt to a lot. If you talk softly it means you are not confident. Year by year I try to open up my opinions, especially with my husband.' Sandra, socialised within the Cambodian culture to adopt certain linguistic practices appropriate to her gender in that society, must decide now for herself how willing she is to follow the practices of native speakers in the target culture to express gender. Talking softly seems to have a strong correlation with the expression of a desirable submissive feminine identity in Cambodia, yet New Zealand perceptions of talking softly are often also associated with lack of confidence, lack of conviction, and lack of power. It seems that Sandra's Kiwi husband encourages Sandra's gender re-negotiation processes through conversations and job sharing in the household, thus giving evidence of the important place interlocutors play in the process of cultural adaptation.

Leo, originally from Tibet, a New Zealand resident for 19 years and married to an Australian, refers to his adjustment process with wry humour. He has successfully negotiated and co-constructed a new gendered identity 
for himself within his intimate relationship, evident by the frankness with which he talks about it: 'You know my wife says that she wishes she had married a "real" man (laughs). I have tended to support it myself. She's the boss, you know, and in every matter I tend to consult her and do it. She is also very direct. She tells me off, more often than not, so I have lost that manly dignity, if there is one. I don't consider myself the boss of the family.' Leo is well aware that adjustment to what he perceives as targetculture gender ideologies has cost him what he calls his 'manly dignity', what might alternatively be termed the patriarchal power of the male in the intimate relationship and in the family domain. This loss of access to a traditional source of power may cause male immigrants, in particular, to experience dramatic identity shifts. ${ }^{67}$ Indeed, Leo's statement about his co-constructed intimate relationship sphere shows him repositioned away from a traditional, Tibetan gender ideology space as head of the family.

These data show that participants engage in negotiation and construction of new gender identities in the domain of intimate relationships on a variety of different levels, experiencing both difficulties and successes. One's cross-cultural partner is a powerful co-constructor in this setting, as some individuals' statements suggest here, especially Sandra's husband, Sola's interlocutors, and Leo's wife. Immigration and cross-cultural intimate relationships may be experienced as a welcome opportunity to escape restrictive traditional gender roles and a place where immigrants can negotiate and construct new gendered identities, as Regina's statement shows. Alternatively, when confronted with new linguistic and new cultural realities, traditional male power and authority may experience fluidity and instability, ${ }^{68}$ as both Harold's and Leo's examples show, although this is perceived to be less of a problem and more of an opportunity.

In each of the excerpts, informants highlight differences in target-culture gender ideologies as they perceive them and as these differences clash with their own ideologies. It seems clear that each informant is being affected by these differences, and each moves differently to adjust the performance of gender.

\section{Discussion of parent-child relationships}

In this section, the participants' parent-child relationships in terms of language choice are presented and discussed. Burck ${ }^{69}$ suggests that first and childhood languages are the most intimate and emotionally expressive in relation to parenting, and one would expect that immigrants prefer to parent in their L1, but the analysis below shows that this is not necessarily the case.

The present writer's experience (originally from Switzerland, and resident in New Zealand for the past 24 years) reflects a position between tradition 
and change resulting from a rejection of particular culturally and socially gendered identities in her source culture, combined with a positive choice for a shift to the target language and culture. Burck's ${ }^{70}$ suggestion that a partner's language may be as much an influence on the choice of language(s) transmitted to children in the home as any outside factor, applies here, coupled with a strong desire to adapt to the target culture. Language use in this family is significantly interlinked with the mother's gendered identityconstruction, in particular a rejection of traditional mothering practices:

Sonya: We agreed not to continue using Schweizerdeutsch (Swiss German) with our three-year-old son when we returned to live in New Zealand. This for a variety of reasons: wanting to assimilate into the target culture as quickly as possible; to help our son learn English as quickly as possible; to accommodate my English husband who associated the sound of the (Swiss German) language with his rather negative experiences in Switzerland; and to leave my restricting Swiss upbringing behind me and reinvent myself as a new woman. Mothering my three children in English has allowed me to distance myself from my parents' parenting practices. I have learned to use the English language as a means to parent differently, more emotionally expressive and certainly less critical.

For Leo, language choice, language use and gendered identity are also clearly intertwined:

My children mainly speak English. Unfortunately, they don't understand my Tibetan. That's because my wife and myself have spoken English all the time at home, so I consider that as my failure as a father.

The question of language is inextricably linked with the question of nationality and therefore of identity. Leo views his language shift in the parent-child relationship as an unfortunate event and considers it a point of failure as a father towards his children, whereas the present writer perceives the shift to the target language and target-culture gender ideologies as a positive result. Both informants' partners speak English as a first language, and both informants have chosen to parent in English, thus re-enforcing a change in their respective gender identities.

Sandra finds herself in a situation of cross-cultural tension in relation to her children, who were born in Cambodia and moved to New Zealand with her when they were teenagers. They have initiated change in Sandra's parenting ideologies by adopting eagerly the new social identities available to them in the target culture, and thus they have become co-constructors of Sandra's parenting identity. Sandra's parenting ideologies are patterned on those of her native Cambodia, and her values are those with which she herself was brought up. She is clearly aware of the tensions her parenting 
ideology creates within her family: 'In our culture we are afraid to look straight eye contact with our parents. They find it very rude. I still keep this attitude, this culture, because I came here in old age. But I don't mind with my children. If they do it with me, and it's not too rude, it's a thing that's okay.' Sandra's perception of the target-culture values and the opportunities this country offers to her children influences her traditional parenting ideologies to the extent that she, however reluctantly, can accept her children's discourse practices even when they are directly opposed to her own values.

John, a Malaysian Chinese and a New Zealand resident for the past nine years, does not find this transition as easy to bridge as Sandra. In John's mind, parents occupy a position of authority and power over children, a parenting ideology prevalent in his source culture. John has observed New Zealand parents behave in ways that undercut this ideology, thereby unbalancing the parent-child relationship pattern he values: 'I have seen Kiwi parents - they find it quite easy to say "sorry" to their children. In my culture, my dad, my mum ..., they would not say "sorry" to their children. The parents are always in a position of authority.'

The parent-child relationships examined here illustrate a variety of reactions in informants when faced with target-culture influences: Leo's regret for the missed opportunity of passing on his native language and culture; the present writer's distancing herself from her L1 and her parents' parenting ideologies and embracing the parallel opportunity of reinventing herself as a new woman and mother; Sandra's adherence to traditional parenting values and the tension created by her children's assimilation to the target culture; and John's resistance to what he sees as negative parenting values in comparison with his source-culture parenting ideologies. Children are important co-constructors in immigrant parents' linguistic and parenting practices, often introducing change and language shift away from traditional values. Immigrant parents' gendered identity is firmly linked with their parenting ideologies and values, and both mothers and fathers may find their gendered identities as parents challenged by their children's rapid acculturation processes, as is borne out in a wealth of New Zealand immigrant and migration literature. ${ }^{71}$

\section{Discussion of friendship networks}

This section reveals that interactions with target-culture friends can be a difficult terrain to navigate in a second language, and a more difficult setting still in which to enact the gendered identity one wishes to display. Paula, originally from Singapore and a New Zealand resident for nine years, adopts a cautious approach in connection with her target-culture friendship network, resists assimilation, and instead insists on being understood on her 
own terms: 'With girls I may share more about girls' stuff, but I'm still more conservative than what I would share at home. What I find inappropriate in the culture here, talking too much about myself or my views, I tend to scale down, I tend not to share too much or too openly, maybe especially with people that I don't know too well.' Discourse that is performed easily and confidently in one's own language and culture background may become complex and difficult to negotiate cross-culturally and in a second language. New identity-construction processes may be hindered by a lack of ease with new gender ideologies - in Paula's case, the target-culture's reticence in discussing oneself or one's views. At the same time, Paula's target-culture friendship network provides her with a context within which she is allowed to test out new gendered identities - whether she takes up these opportunities or not is ultimately up to her.

Resistance to constructing a new gendered identity modelled on targetculture practices may be caused by a realisation that target-culture practices are far less liberal or liberating than an individual's source-culture practices. Denise, originally from Switzerland and a New Zealand resident for the past 30 years, experienced a friendship domain in New Zealand quite unlike the one she was used to back home: 'When we came here it felt like that girls and women were in one group, and men very much in another group, and one couldn't switch easily, especially at parties. There was always this women's corner and the men's corner and I just couldn't understand that for the life of me, why when you go to a party are you separated rather than mingling and getting to know everybody.' Although Denise's statement refers to her cross-cultural social contact at the beginning of her new life in New Zealand, it gives a snapshot of a target-culture friendship network that is markedly different from what she was used to. By highlighting her difficulties with prevalent target-culture gender ideologies as she found them, she is expressing her resistance to them and a willingness to introduce her own source-culture gender ideologies into this particular friendship network.

Denise's husband Will, also from Switzerland and a New Zealand resident for 30 years, is party to similar social experiences and finds the expression of gender in New Zealand hampering: 'You certainly don't talk with (New Zealand) men about your feelings, unless you know that you can. It's often here men, if you don't know them too well, it's all they talk about is work or rugby or sport, and you feel there isn't much other interest, you know.' Will's New Zealand friendship network presents a picture of limited discourse possibilities and a somewhat limiting gender framework, similar to Denise's experience. Both realise their choice of resisting these restrictions and of presenting self-expressions that are less co-construction with targetculture interlocutors than an insistence on representing other values. As an immigrant couple from the same source-culture background, they can be 
co-constructors together; single immigrants who enter the target culture alone do not necessarily have such support available.

Freya, originally from Brazil and a New Zealand resident for the past seven years, finds herself in a position of half-assimilation, half-resistance, torn between the wish to assimilate to her New Zealand husband's culture and the maintenance of her gendered identity co-constructed in her native country. This conflict results in constant tension and vigilance to control her Brazilian-ness: 'When I came here I realised that "Oh my God I speak so loud!", so all the time I need to control myself. I think that I came here, so I have to change, not they have to accept me the way I am, so I changed a lot. If I'm like them, they will accept me more, and it's quite sad actually, I think, because I should be myself. I think it's very isolated here.' Freya's situation is one of 'being stuck in-between', where she denies herself the free and frank expression of her source-culture gender ideologies that include voice levels and gesturing, instead changing herself 'a lot' to be accepted by her target-culture interlocutors, thinking that she will be liked better. It is small wonder that she experiences these attempts at adjustment as sad, that she would much prefer to be herself, and that she finds New Zealand a very isolated place in which to live. She implies that her target-culture interlocutors are enforcing these changes on her, and at the same time it is she herself, in an attempt to assimilate, who submits herself to these changes in her gendered identity.

Immigrants are sometimes forced into change, because different audiences require different performances, as Freya's example shows; all kinds of different 'selves' are possible, because the target culture offers us a wide range of ways of being - and all these ways of being are gendered. ${ }^{72}$ This section reveals that the friendship network is a social domain in which immigrants may experiment with constructing new gendered identities, adapt to some, and resist or reject others. This construction happens always in reference to one's native cultural gender ideologies; in the data presented above we find Paula's, Denise's and Will's resistance to, or at least suspicion of, target-culture gender ideologies and that they thereby introduce subtle changes into the prevailing gender ideologies. Social and cultural changes are possible precisely because "we do not use the discourses available to us uncritically, but participate actively in the construction of meaning. ${ }^{73}$

\section{Summary and conclusion}

Increasing attention to immigrants' gender negotiation and construction processes provides exciting new perspectives on identity-construction in the multilingual context. New Zealand is a comparatively new setting in which to observe and analyse immigrants' acculturation processes. Immigrants who do not have a social network of family and friends in New Zealand 
are under greater pressure, self-imposed or from members of the target culture, to adjust to and assimilate into target-culture gender practices. This study shows informants' gender identity adjustment processes in a variety of domains: intimate relationships, parent-child relationships, and friendship networks. The findings show that these three domains are indeed rich grounds in which informants negotiate and construct new gendered identities. The more intimate the domain, the more difficult informants find the re-negotiation of their gendered identities, unless informants are seeking to adapt to target-culture gender ideologies in an attempt to escape from their more restrictive source-culture gender ideologies. Alternatively, they resist adjustment, because the gender ideologies prevalent in their social field in New Zealand are not as desirable to them, or they position themselves between two conflicting gender ideologies, grappling with adjustments. The findings show that these adult immigrants engage in a re-negotiation process of their gendered identities vis-à-vis target-culture interlocutors and that this process of cultural adaptation is complex and difficult.

The acquisition of the English language itself is only an introduction to identity (re)construction processes which are, even for long-term New Zealand immigrants, ongoing, complex, and flexible, of which the transformation of gender performance is an important aspect. This study has departed from the usual practice of examining either femininities or masculinities in various discourse settings, or the construction of gendered ethnolinguistic identities through various languages. Instead, it has explored a poststructuralist understanding of informants' subjective experiences of gender identity renegotiation as they meet target-culture gender ideologies. On the basis of the data collected for this study, it appears that both male and female immigrants from a cross-section of different cultural backgrounds experience similar issues in adjusting to target-culture gender practices. Individuals either internalise or resist them, depending on the perceieved desirability of target cultural practices or on encouragement by co-constructing interlocutors, be they partners, children, or friends. As tempting as it is to draw generalised conclusions about European or Asian immigrants as a group, the study shows that within a cultural group there are different experiences, due to different personalities, expectations, and interlocutors within the different social domains.

To conclude, gender negotiation and construction processes in adult long-term immigrants to New Zealand are an interesting field of study that could benefit from more research to further illustrate the diverse experiences immigrants have in this country, as part of their continuing acculturation process to its multicultural context. By investigating these experiences, we may know more about New Zealanders in the making, as well as about New Zealanders who consider themselves 'there' already. 


\section{If I'm Like Them, They Will Accept Me More}

1 I wish to thank my interviewees for their willingness to share their stories with me. Thanks to Dr. Jae Song and Dr. Donna Starks for comments and encouragement and to two anonymous reviewers for their helpful critique on an earlier draft.

2 Judith Butler, Gender Trouble: Feminism and the Subversion of Identity, London, 1990.

3 B.N. Peirce, 'Social Identity, Investment, and Language Learning', TESOL Quarterly (TESOLQ), 29 (1995), pp.9-31; Aneta Pavlenko, 'How Am I to Become a Woman in an American Vein?: Transformations of Gender Performance in Second Language Learning' in A. Pavlenko, A.J. Blackledge, I. Piller and M. Teutsch-Dwyer, eds, Multilingualism, Second Language Learning, and Gender, Berlin and New York, 2001, pp.133-74.

4 L. Milroy, Language and Social Networks, Oxford, 1980.

5 I. Piller and A. Pavlenko, 'Bilingualism and Gender', in T.K. Bhatia and W.C. Ritchie, eds, The Handbook of Bilingualism, Oxford, 2004, p.489.

6 Pavlenko, 'Transformations of Gender Performance', p.141.

7 Deborah Cameron, Feminism and Linguistic Theory, London, 1992 and 1996.

8 Janet Holmes, ed., Gendered Speech in Social Context: Perspectives from Gown and Town, Wellington, 2000; Janet Holmes, Gendered Talk at Work: Constructing Gender Identity through Workplace Discourse, New York and Oxford, 2006.

9 A. Pauwels, ed., Women and Language in Australian and New Zealand Society, Sydney, 1987; J. Winter and A. Pauwels, 'Gender and Language Contact Research in the Australian Context', Journal of Multiulingual and Multicultural Development (JMMD), 21, 6 (2000), pp.508-22; J. Winter and A. Pauwels, 'Gender in the Construction and Transmission of Ethnolinguistic Identities and Language Maintenance in Immigrant Australia', Australian Journal of Linguistics (AJL), 25, 1 (2005), pp.153-68. See also A. Pauwels, J. Winter, and J. Lo Bianco, eds, Maintaining Minority Languages in Transnational Contexts, Basingstoke and New York, 2007.

10 Winter and Pauwels, 'Gender and Language', p.153.

11 K.A. Davis and E. Skilton-Sylvester, 'Looking Back, Taking Stock, Moving Forward: Investigating Gender in TESOL', TESOLQ 38, 3 (2004), p.384.

12 R. Lakoff, 'Language and Woman's Place', Language in Society (LS), 2 (1973), pp.45-80.

13 V. Bergvall, 'Toward a Comprehensive Theory of Language and Gender', LS, 28 (1999), pp.273-93; Deborah Tannen, Gender and Discourse, New York, 1994.

14 Deborah Tannen, Gender and Conversational Interaction, New York, 1993.

15 S. Faludi, Stiffed, New York, 1999.

16 S. Johnson and U.H. Meinhof, eds, Language and Masculinity, Oxford, 1997; S. Johnson, 'Theorizing Language and Masculinity: A Feminist Perspective', in S. Johnson and U.H. Meinhof, eds, Language and Masculinity, Oxford, 1997, pp.130-43.

17 D. Cameron, 'Demythologizing Sociolinguistics: Why Language Doesn't Reflect Society', in J. Joseph and T. Taylor, eds, Ideologies of Language, London and New York, 1990, pp.79-93; D. Cameron, Feminism; D. Cameron, Verbal Hygiene, London and New York, 1995.

18 J. Coates, Women, Men, and Language, London, 1993; J. Coates, “"Thank God I'm a Woman": The Construction of Differing Femininities', in D. Cameron, ed., The Feminist Critique of Language: A Reader, London, 1998, pp.295-320.

19 M. Bucholtz, A.C. Liang and L. Sutton, Reinventiung Identities: The Gendered Self in Discourse, New York and Oxford, 1999. 


\section{Journal of New Zealand Studies}

20 K. Hall and M. Bucholtz, eds, Gender Articulated: Language and the Socially Constructed Self, London and New York, 1995.

21 A.F. Freed, 'Language and Gender', Annual Review of Applied Linguistics (ARAL), 15 (1995), pp.1-20.

22 Holmes, ed., Gendered Speech; J. Holmes and M. Meyerhoff, eds, The Handbook of Language and Gender, Oxford, 2003; Holmes, Gendered Talk.

23 B. McElhinny, We All Wear the Blue: Language, Gender and Police Work, Stanford, 1993.

24 Pauwels, 1987.

25 Winter and Pauwels, 'Gender and Language'; Winter and Pauwels, 'Gender in the Construction'.

26 Davis and Skilton-Sylvester, 'Looking Back, Taking Stock', p.383.

27 David Block, 'Identity in Applied Linguistics', in T. Omoniyi and G. White, eds, The Sociolinguistics of Identity, London and New York, 2006, pp.34-49; David Block, Second Language Identities, London and New York, 2007; A. Pavlenko and A.J. Blackledge, eds, Negotiation of Identities in Multilingual Contexts, Clevedon, 2004.

28 Pavlenko, Blackledge, Piller and Teutsch-Dwyer, eds, Multilingualism, p.2.

29 B. Norton, Identity and Language Learning: Gender, Ethnicity and Educational Change, Harlow, 2000; Pavlenko, Blackledge, Piller, and Teutsch-Dwyer, eds; T. Omoniyi and G. White, eds, The Sociolinguistics of Identity, London and New York, 2006.

30 Butler; Cameron, Feminism; Coates, "“Thank God"'; A. Uchida, "When "Difference" Is "Dominance": A Critique of the "Anti-Power-Based" Cultural Approach to Sex Differences', in D. Cameron, ed., The Feminist Critique of Language: A Reader, London and New York, 1998, pp.280-92.

31 V. Burr, An Introduction to Social Constructionism, London, 1995.

32 Uchida; P. Eckert and S. McConnell-Ginet, Language and Gender, Cambridge, 2003.

33 W.B. Gudykunst and S. Ting-Toomey, Culture and Interpersonal Communication, California, 1988, p.13.

34 Burr, Social Constructionism, p.4.

35 Pavlenko, 'Transformations of Gender Performance' pp.133-4; J. Benson, 'Reinterpreting Gender: Southeast Asian Refugees and American Society', in L. Camino and R. Krulfeld, eds, Reconstructing Lives, Recapturing Meaning: Refugee Identity, Gender, and Culture Change, Basel, 1994, pp.75-96; D. Gordon, 'Shifting Gender Roles in the Acculturation Process', University of Pennsylvania Working Papers in Educational Linguistics (UPWPEL), 11, 1 (1995), pp.50-68; R. Krulfeld, 'Buddhism, Maintenance and Change: Reinterpreting Gender in a Lao Refugee Community', in L. Camino and R. Krulfeld, eds, Reconstructing Lives, Recapturing Meaning: Refugee Identity, Gender, and Culture Change, Basel, 1994, pp.97-127; J. Ledgerwood, 'Changing Khmer Conceptions of Gender: Women, Stories, and the Social Order', Phd thesis, Cornell University, New York, 1990; A. Lieblich, 'Looking at Change: Natasha, 21: New Immigrant from Russia to Israel', in R. Josselson and A. Lieblich, eds, The Narrative Study of Lives, (Narrative Study of Lives I), Newbury Park, Ca., 1993, pp.92-129.

36 For a comprehensive list of publications see Te Ara - The Encyclopedia of New Zealand, Settler and Migrant Peoples of New Zealand, Auckland, 2006, pp.290-4.

37 Norton, p.24.

38 Piller and Pavlenko, p.489. 


\section{If I'm Like Them, They Will Accept Me More}

39 Holmes, Gendered Talk; M. Barrett and M.J. Davidson, Gender and Communication at Work, Aldershot, Burlington, 2006; L. Mullany, Gendered Discourse in the Professional Workplace, Basingstoke, 2007.

40 Butler, Gender Trouble.

41 Pavlenko, 'Transformations of Gender Performance', p.151.

42 Ibid., p.149.

43 Pavlenko, Blackledge, Piller and Teutsch-Dwyer, eds.

44 Pavlenko, 'Transformations of Gender Performance', p.155.

45 Ibid.

46 Cameron, Feminism.

47 Piller and Pavlenko, p.501.

48 C. Burck, Multilingual Living: Explorations of Language and Subjectivity, London, 2005.

49 Piller and Pavlenko, p.499.

50 S. Boyd, 'North Americans in the Nordic Region: Elite Bilinguals', International Journal of the Sociology of Language (IJSL), 133 (1998), pp.31-50.

51 Burck, Multilingual Living, p.136.

52 Burck, Multilingual Living.

53 B. Bönisch-Brednich, Keeping a Low Profile: An Oral History of German Immigration to New Zealand, Wellington, 2002.

54 A.J. Blackledge, Literacy, Power, and Social Justice, Stoke-on-Trent, 2000; A.J. Blackledge and A. Pavlenko, guest eds, Language Ideologies in Multilingual Contexts, Multilingua special issue, 20, 3 (2003); Bucholtz, Liang and Sutton; J.H. Hill, 'Junk Spanish, Covert Racism, and the (Leaky) Boundary between Public and Private Spheres', Pragmatics, 5 (1995), pp.197-212; J.H. Hill, 'Language, Race and White Public Space', American Anthropologist (AA), 100 (1998), pp.680-9.

55 Piller and Pavlenko, p.503.

56 Norton, Identity.

57 Milroy, p.53.

58 K. Charmaz, Constructing Grounded Theory. A Practical Guide through Qualitative Analysis, London, 2006.

59 Burck, Multilingual Living.

60 Thus 'Sonya' is the final participant of the study.

61 Li Wei, 'Methodological Questions in the Study of Bilingualism', in L. Wei, ed., The Bilingual Reader, London and New York, 2000, p. 475.

62 B. Davies and R. Harre, 'Positioning: The Discursive Production of Selves', Journal for the Theory of Social Behaviour (JTSB) 20 (1997), pp.43-63.

63 Pavlenko, 'Transformations of Gender Performance', p.139.

64 J. Mills, 'Mothers and Mother Tongue: Perspectives on Self-Construction by Mothers of Pakistani Heritage', in A. Pavlenko and A.J. Blackledge, eds, Negotiations of Identities in Multilingual Contexts, Clevedon, 2004, p.168.

65 Pavlenko, 'Transformations of Gender Performance', see section 'Intimate Relationships'.

66 Burr, Social Constructionism.

67 D. Gordon, “"I'm Tired, You Clean and Cook": Shifting Gender Identities and Second Language Socialization', TESOLQ, 38, 3 (2004), pp.437-57. 


\section{Journal of New Zealand Studies}

68 M. Teutsch-Dwyer, '(Re)constructing Masculinity in a New Linguistic Reality', in Pavlenko, Blackledge, Piller and Teutsch-Dwyer, eds, pp.175-98.

69 Burck, Multilingual Living.

70 Ibid, see section 'Parent-Child Relationships'.

71 Te Ara, Settler and Migrant Peoples of New Zealand.

72 Coates, 'Construction'.

73 Coates, “"Thank God"', p.302. 